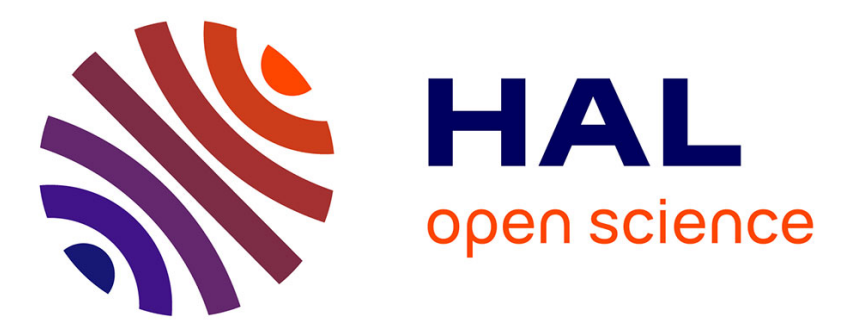

\title{
High prevalence rates of tobacco, alcohol and drug use in adolescents and young adults in France: results from the GAZEL Youth study.
}

Maria Melchior, Jean-François Chastang, Pâquerette Goldberg, Eric Fombonne

\section{To cite this version:}

Maria Melchior, Jean-François Chastang, Pâquerette Goldberg, Eric Fombonne. High prevalence rates of tobacco, alcohol and drug use in adolescents and young adults in France: results from the GAZEL Youth study.. Addictive Behaviors, 2008, 33 (1), pp.122-33. 10.1016/j.addbeh.2007.09.009 . inserm-00226396

\section{HAL Id: inserm-00226396 https://www.hal.inserm.fr/inserm-00226396}

Submitted on 30 Jan 2008

HAL is a multi-disciplinary open access archive for the deposit and dissemination of scientific research documents, whether they are published or not. The documents may come from teaching and research institutions in France or abroad, or from public or private research centers.
L'archive ouverte pluridisciplinaire HAL, est destinée au dépôt et à la diffusion de documents scientifiques de niveau recherche, publiés ou non, émanant des établissements d'enseignement et de recherche français ou étrangers, des laboratoires publics ou privés. 


\title{
High prevalence rates of tobacco, alcohol and drug use in adolescents and young adults in France: results from the GAZEL Youth study.
}

\author{
Maria Melchior ${ }^{1,2}$, Jean-François Chastang ${ }^{2}$, \\ Pâquerette Goldberg ${ }^{2}$, Eric Fombonne ${ }^{3,4}$
}

\footnotetext{
${ }^{1}$ MRC Centre for Social, Genetic and Developmental Psychiatry, Institute of Psychiatry, King's College, POBOX 080 De Crespigny Park, SE5 8AF, London ,United Kingdom (maria.melchior@iop.kcl.ac.uk);

${ }^{2}$ INSERM, U687, 14, rue du Val d'Osne, Saint-Maurice, F-94410, France; Université Paris XI, IFR69, Villejuif, F-94807, France ; (jeanfrancois.chastang@st-maurice.inserm.fr)

${ }^{3}$ Department of Psychiatry, McGill University, 1033 Pine Avenue West, Montreal, Quebec, H3A 1A1,Canada (eric.fombonne@mcgill.ca);

${ }^{4}$ Department of Psychiatry, Montreal Children's Hospital, Centre universitaire de santé McGill 2300, rue Tupper, Montréal, Québec, H3H 1P3, Canada
}

Corresponding author: Maria Melchior, Institute of Psychiatry, Social, Genetic and Developmental Psychiatry Centre, BOX p080, De Crespigny Park, London SE5 8AF, tel: +(00)44 (0) 207848 0595; Fax: (0044) (0)20 7848 5262; Email:

maria.melchior@iop.kcl.ac.uk 


\begin{abstract}
Background: Rates of substance use among adolescents have increased in the 1990s, however little is known about current patterns of substance use among youths entering adulthood.

Methods: We studied sex and age-specific rates of substance (tobacco, alcohol, cannabis, other illicit drugs, inhalants and psychotropic medications) use in a large sample of French youths aged 12-26 years (the GAZEL Youth study, $n=1333)$.
\end{abstract}

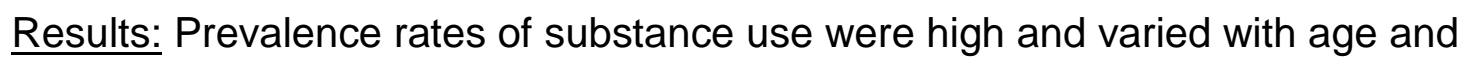
sex. Tobacco, cannabis and polysubstance use were most frequent among 1921 year-olds (regular tobacco use: $41.5 \%$ in males, $39.9 \%$ in females; regular cannabis use: respectively $23.9 \%$ and $10.9 \%$; tobacco + alcohol + cannabis: respectively $9.9 \%$ and $4.6 \%$ ). Regular alcohol use was most frequent among 22 26 year-olds (29.8\% in males, $15.6 \%$ in females). Across successive birth cohorts, the age of initiation of tobacco and cannabis use decreased. Males were consistently more likely to use psychoactive substances than females (except for tobacco and psychotropic medications).

Conclusions: Rates of substance abuse peak in late adolescence but remain high among a subgroup of young adults. Moreover, substance use initiation appears to be occurring at increasingly younger ages.

Key words: adolescents; young adults; alcohol; cannabis; illicit drugs; epidemiology 


\section{Introduction}

Adolescence is a period of high risk for the initiation of tobacco, alcohol and illicit drug use. In recent years, rates of adolescent substance use appear to have increased across industrialized countries (Bachman et al., 1998; Beck et al., 2004; Choquet et al., 2004). Moreover, there is evidence that youths start using psychoactive substances at earlier ages than in the past (Monshouwer et al., 2005; Perkonigg et al., 2006). This is of concern because adolescents who regularly use psychoactive substances are at high risk of substance-related abuse or dependence, as well as employment problems and delinquency later in life (Ellickson et al., 2003; Perkonigg et al., 1999; Riala et al., 2004). The earlier substance use is initiated the worse the adult outcomes (Arseneault et al., 2002; Ellickson et al., 2003).

In order to understand youths' patterns of substance use, it is essential to describe them in detail. As levels of substance use in the population change over time, only studies that compare youths of different ages at a single point in time can assess age- and cohort-related trends. To date, research has mostly focused on substance use among adolescents, and there is still need for additional data pertaining to young adults (Perkonigg et al., 2006).

Our study is set in France, where adolescents' rates of substance use are among the highest in Europe - particularly tobacco and cannabis use. According to national surveys, approximately $35 \%$ of French $16-18$ year olds daily smoke cigarettes and about $20 \%$ regularly use cannabis (Beck \& Legleye, 2003; Choquet et al., 2000). French youths are also more likely than youths from 
Northern European countries to concurrently use several psychoactive substances (Choquet et al., 2004; Hibell et al., 2000). However, past research either focused on school-aged adolescents (ages 14-18) (Beck et al., 2004; Choquet et al., 2004; Choquet et al., 2000; Ledoux et al., 2002) or combined adolescents and young adults into one broad category (ages 15-25) (INPES, 2001) and patterns of substance use among young adults in France have not been documented.

The aim of our study is to describe patterns of tobacco, alcohol, and illicit drug use in relation to age and sex in a large sample of French youths aged 1226 years.

\section{Methods}

\subsection{Study population}

Participants were drawn from the GAZEL Youth study, which aims to examine mental health and substance use in a large, nationwide, sample of youths in France. As previously described, participating youths were recruited in 1991, via their parents, who take part in an ongoing epidemiological study: the GAZEL cohort (Fombonne \& Vermeersch, 1997; Goldberg et al., 2007 ). The GAZEL Youth study sample was selected to represent the socio-demographic characteristics of French youths. The original cohort consisted of 2582 girls and boys aged 4-16 years in 1991. A follow-up assessment was conducted in 1999, when participants were aged $12-24$ years (44.5\% response rate; additionally 213 youths who had not participated in the baseline assessment, including 50 youths aged 25 or 26 years, took part in the follow-up) (Galera et al, 2005). Study 
response rates are typical of mental health surveys conducted in France (ESEMED)(Alonso et al., 2004). In 1999, response rates were somewhat higher among females than among males, among younger youths (aged 12-18 years) than among older youths (aged 19-24 years), among youths from socioeconomically-privileged backgrounds than among youths from socioeconomically-disadvantaged backgrounds (Galera et al., 2005). However, 1999 response rates did not vary as a function of mental health or other characteristics.

Our aim in this report is to describe patterns of tobacco, alcohol, and drug consumption among adolescents and young adults. We therefore use information collected when all participants were adolescent or older, that is at the time of the study's follow-up assessment. After excluding 28 participants with missing substance use data, our sample comprises 1333 youths.

2.2 Measures of tobacco, alcohol, and drug use

Substance use data were collected via mailed self-completed questionnaires. All participants were asked about their use of tobacco and alcohol. Youths older than 15 years were also asked to report on their use of illicit drugs (cannabis or marijuana, hallucinogens, amphetamines, ecstasy, cocaine, heroin), inhalants (glue, solvents, aerosols), and prescription medications used without medical supervision (barbiturates, tranquilizers, narcotics). Participants who reported using tobacco or drugs were additionally asked about the age at which they used the substance for the first time. The study questionnaire was 
adapted from the 'Monitoring the Future' survey conducted in the United States (Johnson et al., 1995).

\subsubsection{Tobacco}

Lifetime tobacco use was ascertained by the following question: 'Are you a smoker or have you ever smoked a cigarette?'. Youths who had ever smoked were asked about the number of cigarettes they smoked in the 12 months preceding the study. We defined regular tobacco use as at least one cigarette per day in the 12 months preceding the study.

\subsubsection{Alcohol}

Alcohol use was ascertained by the following questions : 'How many times have you drunk alcoholic drinks such as wine, beer, cider, liquor, cocktails ever? in the past 30 days?' We defined lifetime alcohol use as the consumption of at least one alcoholic drink ever. We defined regular alcohol use as more than 10 alcoholic drinks in the 30 days preceding the study. Binge drinking was ascertained by the following question 'In the past two weeks how many times have you drunk 5 alcoholic drinks or more in one sitting?' . Alcohol abuse was ascertained by the following questions: 'How many times have you drunk alcohol to the point of being drunk - ever? in the 30 days preceding the study?'.

\subsubsection{Cannabis or marijuana}

Cannabis or marijuana use (referred to as cannabis use from here on) was ascertained by the following questions: 'How many times have you used cannabis - ever? in the past 12 months? in the past 30 days?'? We defined lifetime cannabis use as the use of cannabis on at least one occasion ever. We 
defined regular cannabis use as the use of cannabis on at least 10 occasions in the 12 months preceding the study and very frequent use as the use of cannabis on at least 10 occasions in the 30 days preceding the study.

2.2.4. Illicit drugs other than cannabis, inhalants and prescription medications

The use of illicit drugs other than cannabis (LSD, amphetamines, ecstasy, cocaine, heroin) was ascertained by the following questions: 'How many times have you used - LSD? amphetamines? ecstasy? cocaine? heroin?'. The use of inhalants (glue, solvents, aerosols) was ascertained by the following question: 'How many times have you used inhalants'? The use of prescription medications used without medical supervision (barbiturates, tranquilizers, narcotics) was ascertained by the following question: 'How many times have you used prescription medications?'. Due to low prevalence rates, we only studied lifetime use of these substances, defined as use on at least one occasion ever.

2.2.5. Polysubstance use

We defined polysubstance use as the regular use of at least two psychoactive substances: tobacco+alcohol, tobacco+cannabis, alcohol+cannabis, or tobacco+alcohol+cannabis.

\subsection{Statistical analysis}

We studied the prevalence of tobacco, alcohol, and drug use across 4 age groups (12-15, 16-18, 19-21, 22-26 years). In addition, among participants who reported lifetime substance use, we studied the age at first use.

Age-related patterns of substance use vary by sex; therefore we studied males and females separately. However, we found no sex differences in the age 
at first substance use so for these analyses we combined both sexes. We tested overall age differences with the chi-square test statistic. To compare the prevalence of substance use in males vs. females, we used logistic regression (females constituted the reference group). Variations in the mean age at first substance use across successive birth cohorts were tested using ANOVAs. Because the age at first substance use is by definition lower in younger age groups, we verified the robustness of our findings using Cox proportional hazards models.

The GAZEL Youth study received the approval of France's national committee for data protection (CNIL: Commission Nationale Informatique et Liberté).

\section{Results}

Our study population consisted of 600 males and 733 females aged 12-26 years. $16.4 \%$ lived in a rural environment, $42.5 \%$ in a town of 2000 to 30000 inhabitants, and $41.1 \%$ in a town of over 30000 inhabitants. A majority $(99.0 \%$ of those aged under 18 and $61.4 \%$ of those aged 19 or older) lived with their parents. Among 12-18 year-olds, 93.6\% attended secondary school, $2.7 \%$ were enrolled at university and $4.1 \%$ were in vocational training. Among 19-26 yearolds, $9.7 \%$ were enrolled in secondary school, 55.7\% attended university, 5.4\% were in vocational training, $22.6 \%$ were employed, and $5.4 \%$ were unemployed.

(Insert Table 1 here)

Table 1 shows associations between age and tobacco, alcohol, and cannabis use. Age was significantly associated with lifetime and regular tobacco 
use ( $p$-values: <0.0001), lifetime and regular alcohol use ( $p$-values: <0.0001), binge drinking ( $p$-values: <0.0001), drunkenness ( $p$-values for lifetime drunkenness: $<0.0001 ; p$-values for drunkenness in the preceding 30 days: $<0.0001$ in young men and 0.0031 in young women). Rates of tobacco use were highest in 19-21 year-olds. Rates of alcohol use and binge drinking were highest in $22-26$ year-olds. Overall, $40.3 \%$ of males and $18.0 \%$ of females aged $22-26$ years reported binge drinking in the 15 days preceding the study. Rates of drunkenness in the 30 days preceding the study were highest among 19-21 yearolds (26.1\% in males; $11.9 \%$ in females). Among regular users of alcohol, respectively $71.3 \%$ of males and $46.7 \%$ of females also reported binge drinking in the preceding 15 days and respectively $44.6 \%$ and $30.0 \%$ reported being drunk on at least one occasion in the preceding 30 days.

Rates of cannabis use were associated with age in males but not in females ( $p$-values for lifetime cannabis use: respectively 0.0004 and $0.086 ; p$ values for regular cannabis use: 0.044 and 0.41 ). Overall, the use of cannabis use was most frequent among $19-21$ year-olds: $54.9 \%$ of males and $42.8 \%$ of females in this age group reported lifetime cannabis use and respectively $23.9 \%$ and $10.9 \%$ reported regular cannabis use. Among regular cannabis users, $46.3 \%$ of males and $37.7 \%$ of females used cannabis on 10 or more occasions in the 30 days preceding the study.

Rates of substance use were higher among males than among females (age-adjusted ORs ranging from 1.46 for the lifetime prevalence of drunkenness to 2.61 for regular alcohol use), with the exception of tobacco use which was 
slightly more frequent in females, but the associated ORs did not reach statistical significance.

(Insert Table 2 here)

Table 2 shows rates of lifetime use of illicit drugs other than cannabis, inhalants and prescription medications among participants aged 16 or older. Age was associated with the use of illicit drugs ( $p$-values: 0.031 in males and 0.041 in females), with the highest prevalence among 19-21 year-olds in males (8.5\%) and among 22-26 year-olds in females (7.0\%). We found no statisticallysignificant age differences in the use of inhalants or prescription medications. The use of illicit drugs and inhalants did not significantly vary by sex. Female participants were more likely than male participants to report using prescription medications, but this sex difference fell just short of statistical significance.

The regular use of tobacco, alcohol and cannabis were moderately correlated to one another (correlation coefficients ranging from .22 to .35 ). Associations between age and polysubstance use varied according to the substances examined (Table 3). Rates of regular tobacco and alcohol use were associated with age ( $p$-values: $<0.0001$ in males and females) and overall highest in $22-26$ year-olds (respectively $15.6 \%$ and $9.5 \%$ ). Rates of regular tobacco and cannabis use did not significantly vary with age, due to the fact that the youngest age group (16-18 years) reported already high rates of use. Rates of regular alcohol and cannabis use were significantly associated with age in males but not in females due to the lower baseline rates across age groups ( $p$ values respectively: 0.0019 and 0.080$)$. $19-21$ year-olds were most likely to 
report regular alcohol and cannabis use $(14.0 \%$ in males and $4.6 \%$ in females). Finally, age was also associated with the regular use of tobacco, alcohol, and cannabis ( $p$-values:0.029 in males and 0.034 in females). Rates were highest in $19-21$ year-olds (9.9\% in males; $4.6 \%$ in females). Polysubstance use was consistently more frequent among males than among females (age-adjusted ORs ranging from 1.94 for tobacco and alcohol use and tobacco and cannabis use to 3.32 for regular alcohol and cannabis use). Overall, $41.5 \%$ of males and $37.7 \%$ of females in our study regularly used at least one psychoactive substance. Regular substance use was strongly associated with the use of illicit drugs other than cannabis (age-adjusted ORs among participants who regularly used tobacco, alcohol and cannabis: $31.57 ; 95 \% \mathrm{Cl} 12.20-81.70$ in males; 14.83 ; $95 \% \mathrm{Cl} 4.64-49.28$ in females).

(Insert Table 3 here)

The age at first substance use decreased across successive birth cohorts (except for inhalants) (Figure). On average, 22-26 year-olds reported first smoking tobacco at age 15.4, compared to age 14.9 among 19-21 year-olds, age 13.8 among $16-18$ year-olds and age 12.6 among $12-15$ year-olds $(p<0.0001)$. $57.0 \%$ of $22-26$ year olds, $67.0 \%$ of $19-21$ year olds, and $87.6 \%$ of $16-18$ year olds first smoked tobacco before age 15 (p-value: <0.0001). Similarly, 22-26 year-olds who used cannabis reported first using at age 17.7, compared to age 16.6 among 19-21 year-olds, and age 15.2 among $16-18$ year-olds $(p<0.0001)$. $16.3 \%$ of $22-26$ year olds, $20.3 \%$ of $19-21$ year olds and $60.0 \%$ of $16-18$ year 
olds first smoked cannabis before age 15 ( $p$-value: $<0.0001$ ). Our confirmatory analyses conducted using Cox regression models yielded very similar results.

\section{(Insert Figure here)}

When youths who had not participated in the baseline assessment of the GAZEL Youth study were excluded from the analysis, our results were unchanged, but due to smaller sample sizes statistical power was reduced and some analyses no longer reached the level of statistical significance.

\section{Discussion}

\subsection{Main findings}

Our study shows high rates of substance use in a large, nationwide, cohort of French youths. By age 26 , approximately $49 \%$ of youth had used tobacco, $91 \%$ had used alcohol, and $42 \%$ had used cannabis. Our estimates are comparable to recent data from national surveys of French junior high school and high school students, which reported lifetime rates of substance use of $55 \%$ for tobacco, $81 \%$ for alcohol and $49 \%$ for cannabis (Choquet et al., 2004). Tobacco, cannabis and polysubstance use appear most frequent between ages 19-21, while alcohol use peaks between ages 22-26. Thus, young adulthood remains a period of frequent substance use. Levels of substance use are higher among males than among females, except for tobacco and psychotropic medications. Overall, French youths are more likely to consume cannabis and psychotropic medications than other European youths, pointing to the need to investigate country-specific determinants of substance-related behaviors.

\subsection{Comparison with past research}


In our study, prevalence rates of substance use among school-aged adolescents are somewhat lower than those reported in nationally-representative studies, such as the French section of the European School Survey Project on Alcohol and Other Drugs (ESPAD) study (for instance, in our study $25.5 \%$ of boys aged $16-18$ regularly smoked cigarettes, compared with $33.4 \%$ in ESPAD; 42.3\% had ever been drunk compared with 59.5\%; 34.4\% had ever used cannabis compared with $48.1 \%$, and $14.1 \%$ regularly used cannabis compared with $22.2 \%$ (Choquet et al., 2000)). These differences in prevalence rates may be due to methodological reasons. Although the GAZEL Youth study sample is nationwide, the proportion of youths from socioeconomically-disadvantaged backgrounds is smaller than in the general population. In addition, it may be that youths who are most susceptible to use psychoactive substances did not take part in the study. The advantage of a community sample is that we were able to include youths who do not attend school, either because they have dropped out or because they are working, which allows us to examine rates of substance use among young adults. Finally, GAZEL Youth study participants completed the study questionnaire at home, whereas ESPAD study participants completed the study questionnaire at school. At home, youths may be concerned that their parents will find out their answers, which could lead them to underreport their levels of substance use. To enhance the confidentiality of our questionnaire, we provided participants with prestamped envelopes in which they mailed the questionnaires directly to the research team. Nevertheless, we cannot exclude that participants reported somewhat lower levels of substance use than true. 
Importantly, rates of alcohol and drug use among GAZEL Youth cohort members are overall comparable to those reported in national surveys and high, which in the future will enable us to examine factors that predict substance use in this cohort.

4.3. Age differences in tobacco, alcohol, and drug use

Consistent with prior research, we found that rates of adolescent alcohol use and abuse increase with age (Choquet et al., 2000; Ledoux et al., 2002). However, rates of tobacco, cannabis and polysubstance use were highest among 19-21 year-olds and lower among 22-26 year-olds. As suggested by other studies, substance use may decrease during the transition to adulthood, when youths enter the labor market and establish stable romantic relationships (Chen \& Kandel, 1995; Farrell et al., 2001; Lert \& Fombonne, 1989). Moreover, birth cohort differences may additionally reflect the secular rise in adolescent substance use observed in the 1990s (Bachman et al., 1998; Choquet et al., 2004).

Although, in our study young adults were less likely to engage in substance use than adolescents, in absolute terms their rates of substance use were high: approximately $15 \%$ of men and $7 \%$ of women aged 22 to 26 years regularly smoked cannabis and $10 \%$ and $5 \%$ regularly used tobacco, alcohol, and cannabis. Thus, among adolescents who use psychoactive substances, a subgroup does not desist from regular use in young adulthood.

It is important to distinguish regular substance use from substance abuse. In our study, $71.3 \%$ of males and $46.7 \%$ of females who regularly drank alcohol 
also reported recent binge drinking and respectively $44.6 \%$ and $30.0 \%$ reported being drunk in the preceding month. Similarly, $46.3 \%$ of males and $37.7 \%$ of females who regularly used cannabis did so on 10 or more occasions in the 30 days preceding the study. These youths may be at high risk of substance-related disorders and poor social outcomes in adulthood. To date, few studies have followed adolescents to examine long-term trajectories of substance-related disorders and additional research in this area is greatly needed (Perkonigg et al., 1999; Windle \& Wiesner, 2004).

\subsection{Sex differences}

As other researchers, we found higher rates of alcohol and cannabis use in males than in females (Choquet et al., 2004; Monshouwer et al., 2006; Perkonigg et al., 1998). In France, women perceive alcohol and drug use as more risky than men (Beck et al., 2003) and women's substance use is less well accepted than men's (Ledoux et al., 2002). Yet it is notable that rates of alcohol and drug use in girls have been rising over time, resulting in the progressive narrowing of the sex gap (Choquet et al., 2004).

In our study, females appeared more likely than males to use psychotropic medications. This sex difference could be related to women's perception that psychotropic medications are less harmful than street drugs and to their elevated rates of mood disorders (Beck et al., 2003; Hankin et al., 1998). Compared to their European counterparts, French adolescents have particularly high rates of psychotropic medication use (Hibell et al., 2000). However, the reasons for this trend are not well understood. Tobacco use was slightly more frequent in females 
than in males, but this sex difference was not statistically significant. In 20032004 , the French government increased the price of cigarettes by $75 \%$, which has been associated with a decrease in the prevalence of daily smoking among adolescents, and particularly among girls (Beck et al., 2006). This tendency will need to be confirmed in future research.

\subsection{Age of onset}

We found that younger youths started using tobacco, cannabis and other illicit drugs at an earlier age than older youths, which is consistent with studies conducted in the Netherlands, Germany and the United States (Johnson et al., 2006; Monshouwer et al., 2005; Perkonigg et al., 2006). As other researchers, we assessed the age of first use via retrospective recall, which is generally thought to produce valid data on substance use initiation (Johnston, 2001). Nonetheless, measurement error is possible. Because of the time delay, older youth may remember the age at which they first used a substance less accurately than younger youths. At the same time, substance use is less acceptable among younger youths, and this group may also report starting at an older age. Thus, measurement error probably reduces birth cohort differences in the age of first substance use, which may therefore be even greater than we report.

The reasons why youths appear to start using psychoactive substances earlier than previously are not well understood. One possible explanation is the decrease in the perceived harmfulness of psychoactive substances (Johnson et al., 2006). Early-onset of substance use is associated with the most adverse 
health and social profiles later in life and there is a need to further understand the factors that influence substance use initiation (Arseneault et al., 2002; Ellickson et al., 2003; Riala et al., 2004).

Compared to their European counterparts, French youths have average rates of cigarette smoking and alcohol consumption (ESPAD, 2003). However, among French youths, rates of cannabis and polysubstance use are high and have risen during the 1990s (ESPAD 2003; Ter Bogt et al., 2006). Patterns of substance use, as well as the types of drugs used and their potency vary from country to country (European Monitoring Centre for Drugs and Addiction, 2004; Mission Interministerielle de Lutte contre la Drogue et la Toxicomanie, 2006) and data from different countries are needed to better understand how specific cultural norms, substance availability and access, as well as policies shape trends in youths' substance use (Monshouwer et al., 2005).

\section{Conclusion}

French adolescents and young adults have high rates of tobacco, alcohol and illicit drugs use: approximately $40 \%$ regularly use at least one psychoactive substance. Moreover, substance use is initiated at younger ages than in previous birth cohorts. Research on factors associated with long-term trajectories of substance use is greatly needed. 
Acknowledgements: Funded by the French Institute of Medical Research (INSERM-CNRS: Sociobiomedical Research Program), the National Institute of Mental Health... The authors thank all youths of the GAZEL Youth study and their parents who facilitated data collection. Additionally, we are grateful to Louise Arseneault and Bertrand Redonnet for many insightful comments on previous versions of the manuscript.

Conflicts of interest: The authors declare no conflicts of interest. 


\section{References}

Alonso, J., Angermeyer, M. C., Bernert, S., Bruffaerts, R., Brugha, T. S., Bryson, H. et al. (2004). Prevalence of mental disorders in Europe: results from the European Study of the Epidemiology of Mental Disorders (ESEMeD) project. Acta Psychiatricq Scandinavica Supplement 21-27.

Arseneault, L., Cannon, M., Poulton, R., Murray, R., Caspi, A., \& Moffitt, T. E. (2002). Cannabis use in adolescence and risk for adult psychosis: longitudinal prospective study. British Medical Journal, 325, 1212-1213.

Bachman, J. G., Johnson, L. D., \& O'Malley, P. M. (1998). Explaining recent increases in students' marijuana use: impact of perceived risk and disapproval, 1976 through 1996. American Journal of Public Health, 88, 887-892.

Beck, F. \& Legleye, S. (2003). Evolutions recentes des usages de a 17 ans: ESCAPAD 2000-2002. Tendances, 1-4.

Beck, F., Legleye, S., \& Peretti-Watel, P. (2003). Penser les drogues: perceptions des produits et des politiques publiques. Paris: OFDT.

Beck, F., Legleye, S., \& Spilka, S. (2004). Cannabis, alcool, tabac et autres drogues à la fin de l'adolescence: usages et evolutions recentes ESCAPAD 2003. Tendances, 1-4. 
Beck, F., Legleye, S., \& Spilka, S. (2006). Les drogues à 17 ans. Tendances [On-line]. Available:

http://www.ofdt.fr/BDD/publications/docs/eftxfbm9.pdf\#search=\%22escapa d\%202005\%22

Chen, K. \& Kandel, D. B. (1995). The natural history of drug use from adolescence to the mid-thirties in a general population sample. American Journal of Public Health, 85, 41-47.

Choquet, M., Morin, D., Hassler, C., \& Ledoux, S. (2004). Is alcohol, tobacco, and cannabis use as well as polydrug use increasing in France? Addictive Behaviors, 29, 607-614.

Choquet, M., Ledoux, S., Hassler, C., Beck, F., \& Peretti-Watel, P. (2000). Consommation de substances psychoactives chez les 14-18 ans scolarises: premiers résultats de l'enquête ESPAD 1999, évolution 19931999. Tendances, 6, 1-23.

Choquet, M., Beck, F., Hassler, C., Spilka, S., Morin, D., \& Legleye, S. (2004). Les substances psychoactives chez les collégiens et lycéens: consommations en 2003 et évolutions depuis dix ans. Tendances, 35, 1-6.

Ellickson, P. L., Tucker, J. S., \& Klein, D. J. (2003). Ten-year prospective study of public health problems associated with early drinking. Pediatrics, 111, 949-955. 
ESPAD: the European Survey Project on Alcohol and Other Drugs. (2003). [Online]. Available: http://www.espad.org/diagrambilder/summary.pdf.

European Monitoring Centre for Drugs and Addiction (2004). An overview of cannabis potency in Europe.

Farrell, M., Howes, S., Bebbington, P., Brugha, T., Jenkins, R., Lewis, G. et al. (2001). Nicotine, alcohol and drug dependence and psychiatric comorbidity. Results of a national household survey. British Journal of Psychiatry, 179, 432-437.

Fombonne, E. \& Vermeersch, S. (1997). [Children of the GAZEL Cohort: I-Prevalence of contacts with the medico-educational system for psychological reasons, and associated factors]. Revue d'Epidémiologie et de Sante Publique, 45, 29-40.

Galera, C., Fombonne, E., Chastang, J. F., \& Bouvard, M. (2005). Childhood hyperactivity-inattention symptoms and smoking in adolescence. Drug and Alcohol Dependence, 78, 101-108.

Goldberg, M., Leclerc, A., Bonenfant, S., Chastang, J.F., Shmaus, A., Kaniewski, N., Zins, M. (2007). Cohort profile: the GAZEL cohort study. International Journal of Epidemiology, 36, 32-39.

Hankin, B. L., Abramson, L. Y., Moffitt, T. E., Silva, P. A., McGee, R., \& Angell, K. E. (1998). Development of depression from preadolescence to young 
adulthood: emerging gender differences in a 10-year longitudinal study. Journal of Abnormal Psychology, 107, 128-140.

Hibell, B., Andersson, B., Ahlström, S., Balakireva, O., Bjarnson, T., Kokkevi, A. et al. (2000). The 1999 ESPAD report. Alcohol and other drug use among students in 30 European countries. Pompidou Group, Council of Europe.

INPES. Baromètre santé 2000. Volume 2. Résultats (2001). Vanves: INPES.

Johnson, L. D., O'Malley, P., \& Bachman, J. (1995). National survey results on drug use from the Monitoring the Future Study, 1975-1994. Rockville, MD: National Institute on Drug Abuse.

Johnson, L. D., O'Malley, P. M., Bachman, J. G., \& Schulenberg, J. E. (2006). Monitoring the Future national survey results on drug use, 1975-2005. Volume I: Secondary school students (Rep. No. NIH Publication No. 065883). Bethesda, MD: National Institute on Drug Abuse.

Johnston, T.P., \& Mott, J.A. (2001). The reliability of self-reported age of onset of tobacco, alcohol and illicit drug use. Addiction 96, 1187-1198.

Ledoux, S., Miller, P., Choquet, M., \& Plant, M. (2002). Family structure, parentchild relationships, and alcohol and other drug use among teenagers in France and the United Kingdom. Alcohol \& Alcoholism, 37, 52-60.

Lert, F. \& Fombonne, E. (1989). La toxicomanie. Vers une évaluation de ses traitements. Paris: La Documentation Française. 
Mission Interministerielle de Lutte contre la Drogue et la Toxicomanie (2006).

L'alcool. [On-line]. Available:http://www.drogues.gouv.fr/.

Monshouwer, K., Smit, F., de Graaf, R., van Os, J., \& Vollebergh, W. (2005).

First cannabis use: does onset shift to younger ages? Findings from 1988 to 2003 from the Dutch National School Survey on Substance Use. Addiction, 100, 963-970.

Monshouwer, K., van Dorsselaer, S., Verdurmen, J., Ter Bogt, T., de Graaf, R., \& Vollebergh, W. (2006). Cannabis use and mental health in secondary school children. British Journal of Psychiatry, 188, 148-153.

Perkonigg, A., Pfister, H., Hofler, M., Frohlich, C., Zimmermann, P., Lieb, R. et al. (2006). Substance use and substance use disorders in a community sample of adolescents and young adults: incidence, age effects and patterns of use. European Addiction Research, 12, 187-196.

Perkonigg, A., Lieb, R., Höfler, M., Schuster, P., Sonntag, H., \& Wittchen, H.-U. (1999). Patterns of cannabis use, abuse and dependence over time: incidence, progression, and stability in a sample of 1228 adolescents. Addiction, 94, 1663-1678.

Perkonigg, A., Lieb, R., \& Wittchen, H.-U. (1998). Prevalence of use, abuse and dependence of illicit drugs among adolscents and young adults in a community sample. European Addiction Research, 4, 58-66. 
Riala, K., Hakko, H., Isohanni, M., Järvelin, M.-R., \& Räsänen, P. (2004). Teenage smoking and substance use as predictors of severe alcohol problems in late adolescence and in young adulthood. Journal of Adolescent Health, 35, 245-254.

Ter Bogt, T., Schmid, H., Gabhainn, S. N., Fotiou, A., \& Vollebergh, W. (2006). Economic and cultural correlates of cannabis use among mid-adolescents in 31 countries. Addiction, 101, 241-251.

Windle, M. \& Wiesner, M. (2004). Trajectories of marijuana use from adolescence to young adulthood: predictors and outcomes. Development and Psychopathology, 16, 1007-1027. 
High rates of substance use in French youths

Table 1 Tobacco, alcohol, and cannabis use in French adolescents and young adults: the GAZEL Youth study (1999).

\begin{tabular}{|c|c|c|c|c|c|c|c|c|c|c|c|}
\hline & \multicolumn{5}{|c|}{ Males } & \multicolumn{5}{|c|}{ Females } & \multirow{2}{*}{$\begin{array}{c}\text { Males } \\
\text { vs. Females } \\
\text { Age-adjusted OR } \\
(95 \% \mathrm{Cl})\end{array}$} \\
\hline Age & $\begin{array}{c}12-15 \mathrm{yrs} \\
(\mathrm{n}=141)\end{array}$ & $\begin{array}{l}16-18 \text { yrs } \\
(n=163)\end{array}$ & $\begin{array}{c}19-21 \mathrm{yrs} \\
(\mathrm{n}=142)\end{array}$ & $\begin{array}{c}22-26 \text { yrs } \\
(n=154)\end{array}$ & p-value & $\begin{array}{l}12-15 \mathrm{yrs} \\
(\mathrm{n}=156)\end{array}$ & $\begin{array}{l}16-18 \text { yrs } \\
(n=183)\end{array}$ & $\begin{array}{c}19-21 \mathrm{yrs} \\
(\mathrm{n}=194)\end{array}$ & $\begin{array}{l}22-26 \text { yrs } \\
(n=200)\end{array}$ & $p$-value & \\
\hline \multicolumn{12}{|l|}{ Tobacco } \\
\hline Lifetime tobacco use & 21.9 & 49.7 & 62.0 & 52.0 & $<0.0001$ & 31.4 & 54.6 & 59.8 & 58.5 & $<0.0001$ & $0.82(0.65-1.02)$ \\
\hline $\begin{array}{l}\text { Regular tobacco use: } \\
>=1 \text { cig/day in the preceding } 12 \text { months }\end{array}$ & 4.9 & 25.2 & 41.5 & 29.9 & $<0.0001$ & 9.6 & 26.2 & 39.9 & 35.0 & $<0.0001$ & $0.87(0.68-1.12)$ \\
\hline \multicolumn{12}{|l|}{ Alcohol } \\
\hline Lifetime alcohol use & 78.7 & 93.9 & 97.9 & 100 & $<0.0001$ & 77.6 & 93.4 & 94.3 & 96.5 & $<0.0001$ & $1.35(0.89-2.05)$ \\
\hline $\begin{array}{l}\text { Regular alcohol use: } \\
>=10 \text { times in the preceding } 30 \text { days }\end{array}$ & 2.1 & 6.7 & 28.9 & 29.8 & $<0.0001$ & 1.3 & 4.4 & 9.8 & 15.6 & $<0.0001$ & $2.01(1.85-3.73)$ \\
\hline Binge drinking ${ }^{1}$ in the preceding 15 days & 5.7 & 17.2 & 38.0 & 40.3 & $<0.0001$ & 2.6 & 15.3 & 17.5 & 18.0 & $<0.0001$ & $2.29(1.71-3.05)$ \\
\hline Drunk $>=1$ time ever & 7.8 & 42.3 & 71.1 & 76.0 & $<0.0001$ & 12.2 & 36.6 & 52.6 & 65.5 & $<0.0001$ & $1.46(1.15-1.87)$ \\
\hline Drunk $>=1$ time in the preceding 30 days & 2.9 & 11.0 & 26.1 & 20.1 & $<0.0001$ & 1.3 & 6.0 & 11.9 & 11.5 & 0.0031 & $2.16(1.52-3.09)$ \\
\hline \multicolumn{12}{|l|}{ Cannabis } \\
\hline Lifetime cannabis use & $\mathrm{N} / \mathrm{A}^{2}$ & 34.4 & 54.9 & 52.0 & 0.0004 & $\mathrm{~N} / \mathrm{A}$ & 32.2 & 42.8 & 35.0 & 0.086 & $1.52(1.18-1.95)$ \\
\hline $\begin{array}{l}\text { Regular cannabis use: } \\
>=10 \text { times in the preceding } 12 \text { months }\end{array}$ & $\mathrm{N} / \mathrm{A}$ & 14.1 & 23.9 & 14.9 & 0.044 & $\mathrm{~N} / \mathrm{A}$ & 9.3 & 10.9 & 7.0 & 0.41 & $2.15(1.48-3.12)$ \\
\hline $\begin{array}{l}\text { Very frequent cannabis use: } \\
>=10 \text { times in the preceding } 30 \text { days }\end{array}$ & $\mathrm{N} / \mathrm{A}$ & 6.7 & 11.3 & 7.1 & 0.29 & $\mathrm{~N} / \mathrm{A}$ & 3.9 & 3.1 & 3.5 & 0.93 & $2.52(1.45-4.40)$ \\
\hline
\end{tabular}

\footnotetext{
1 Binge drinking: >=5 alcoholic drinks in one sitting.

2 Only youths older than 15 were asked to report their cannabis and other drug use.
} 
High rates of substance use in French youths

Table 2 Use of illicit drugs other than cannabis, inhalants and prescription medications in French adolescents and young adults: the GAZEL Youth study (1999) (\%, pvalue).

\begin{tabular}{|c|c|c|c|c|c|c|c|c|c|}
\hline & \multicolumn{4}{|c|}{ Males } & \multicolumn{4}{|c|}{ Females } & \multirow{2}{*}{$\begin{array}{c}\text { Males } \\
\text { vs. Females } \\
\text { Age-adjusted OR } \\
(95 \% \mathrm{Cl})\end{array}$} \\
\hline & $\begin{array}{c}16-18 \text { yrs } \\
(n=163)\end{array}$ & $\begin{array}{c}19-21 \mathrm{yrs} \\
(\mathrm{n}=142)\end{array}$ & $\begin{array}{c}22-26 \text { yrs } \\
(n=154)\end{array}$ & p-value & $\begin{array}{c}16-18 \text { yrs } \\
(n=183)\end{array}$ & $\begin{array}{l}19-21 \mathrm{yrs} \\
(\mathrm{n}=194)\end{array}$ & $\begin{array}{c}22-26 \text { yrs } \\
(n=200)\end{array}$ & p-value & \\
\hline \multicolumn{10}{|c|}{ Illicit drugs other than cannabis ${ }^{1}$} \\
\hline Lifetime illicit drug use & 1.8 & 8.5 & 6.5 & 0.031 & 1.6 & 4.6 & 7.0 & 0.041 & $1.28(0.71-2.22)$ \\
\hline \multicolumn{10}{|l|}{ Inhalants ${ }^{2}$} \\
\hline Lifetime inhalant use & 6.1 & 12.0 & 5.8 & 0.088 & 6.6 & 6.7 & 6.0 & 0.96 & $1.24(0.77-1.99)$ \\
\hline \multicolumn{10}{|c|}{ Non-medical use of prescription medications ${ }^{3}$} \\
\hline Lifetime medication use & 2.5 & 4.2 & 5.8 & 0.32 & 4.9 & 6.7 & 9.0 & 0.29 & $0.58(0.33-1.03)$ \\
\hline
\end{tabular}

1 Illicit drugs other than cannabis: LSD, amphetamines, ecstasy, cocaine, heroin.

2 Inhalants: glue, solvents, aerosols.

3 Prescription medications used without medical supervision: barbiturates, tranquilizers, narcotics. 
High rates of substance use in French youths

$13 / 7 / 07$

Table 3 Regular polysubstance use in French adolescents and young adults: the GAZEL Youth study (1999) (\%, p-value)1.

\begin{tabular}{|c|c|c|c|c|c|c|c|c|c|c|c|}
\hline & \multicolumn{5}{|c|}{ Males } & \multicolumn{5}{|c|}{ Females } & \multirow{2}{*}{$\begin{array}{c}\text { Males } \\
\text { vs. Females } \\
\text { Age-adjusted OF } \\
(95 \% \mathrm{Cl})\end{array}$} \\
\hline & $\begin{array}{c}12-15 \mathrm{yrs} \\
\mathrm{n}=141\end{array}$ & $\begin{array}{c}16-18 \mathrm{yrs} \\
n=163\end{array}$ & $\begin{array}{c}19-21 \mathrm{yrs} \\
\mathrm{n}=142\end{array}$ & $\begin{array}{c}22-26 \text { yrs } \\
n=154\end{array}$ & $p$-value & $\begin{array}{c}12-15 \mathrm{yrs} \\
n=156\end{array}$ & $\begin{array}{c}16-18 \mathrm{yrs} \\
n=183\end{array}$ & $\begin{array}{c}19-21 \text { yrs } \\
n=194\end{array}$ & $\begin{array}{c}22-26 \text { yrs } \\
n=200\end{array}$ & $p$-value & \\
\hline Tobacco+alcohol & $<1$ & 3.7 & 14.1 & 15.6 & $<0.0001$ & 0 & 1.6 & 7.7 & 9.5 & $<0.0001$ & $1.94(1.24-3.04)$ \\
\hline Tobacco+cannabis & $N / A^{2}$ & 11.0 & 17.6 & 10.4 & 0.13 & $\mathrm{~N} / \mathrm{A}$ & 7.6 & 9.3 & 4.5 & 0.17 & $1.94(1.27-2.95)$ \\
\hline Alcohol+cannabis & $\mathrm{N} / \mathrm{A}$ & 3.1 & 14.0 & 7.1 & 0.0019 & $\mathrm{~N} / \mathrm{A}$ & 1.1 & 4.6 & 2.0 & 0.080 & $3.32(1.79-6.15)$ \\
\hline Tobacco+alcohol+cannabis & $\mathrm{N} / \mathrm{A}$ & 2.5 & 9.9 & 7.1 & 0.029 & $\mathrm{~N} / \mathrm{A}$ & $<1$ & 4.6 & 2.0 & 0.034 & $2.89(1.48-5.45)$ \\
\hline
\end{tabular}

${ }^{1}$ Regular tobacco use: >=1 cigarette/day in the last 12 months; regular alcohol use: >=10 times in the last 30 days; regular cannabis use: 10 times in the last 12 months.

2 Only youths older than 15 were asked to report their cannabis and other drug use. 
Figure 1 Age at first substance use in French adolescents and young adults: the GAZEL Youth study (1999) (mean)'.
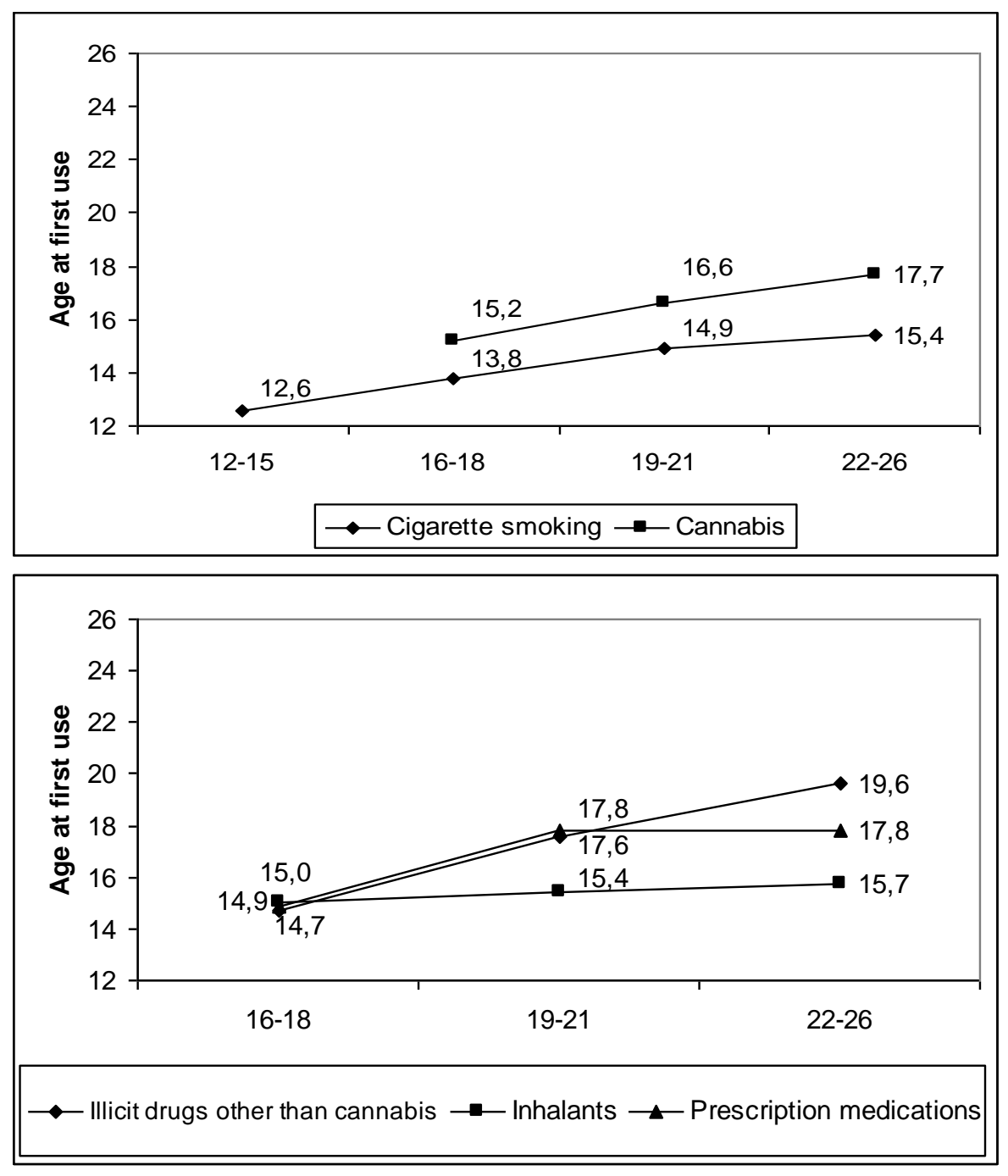

1 Sample size and $p$-value: cigarette smoking: $n=643, p<0.0001$, cannabis: $n=314, p<0.0001$, illicit drugs other than cannabis: $n=36, p<0.0001$, inhalants: $n=36, p=0.74$, prescription medications: $n=33, p=0.0063$. 